\title{
Assessment of Anti Hypertensive Drugs In Ckd Patients
}

\author{
N.Kanaka Durga Devi*, M.Priyanka, A.Swathi, Jasti.Krishna Sai, K.Naveen \\ Babu. \\ KVSR Siddhartha College of Pharmaceutical Sciences, Vijayawada-10, Andhra Pradesh.
}

\begin{abstract}
Hypertension is common in hemodialysis patients and can often be difficult to control. Considering the high cardiovascular burden in hemodialysis patients, control of blood pressure is important to improve outcomes. This study is conducted to assess the anti hypertensive drugs treatment in chronic kidney disease (CKD) patients. This is a prospective observational study and includes information regarding CKD patients with co-morbidities like T2DM and HTN and it is conducted among 15 patients which were of both males and females of above $20 \mathrm{yrs}$ of age upto $80 \mathrm{yrs}$. For these 15 patients e GFR is calculated and stage of severity of CKD was found. Patients with T2DM and Hypertensive are mostly diagnosed with CKD. Loop diuretic (Furosemide)+ calcium channel blocker (Amlodipine) this combination is prescribed more which is found to be safe for CKD patients as for this combination dosage adjustment is not required. In our study among 15 CKD patients 7 dialysis patients were included, majority of the patients have controlled SBP with the antihypertensive combinations.
\end{abstract}

Key-words:- Hypertension, CKD patients, T2DM, Hemodialysis, Amlodipine.

\section{INTRODUCTION:}

Angiotensin - converting enzyme inhibitors (ACEIs) and angiotensin receptor blockers (ARBs) have been shown to decrease mortality and morbidity in patients with congestive heart failure and in patients with acute myocardial infarction ${ }^{1-3}$. They remain the firstline therapy for patients with cardiovascular $(\mathrm{CV})$ disease. Similarly, in patients with diabetic and non-diabetic kidney disease, several large trials have demonstrated their effectiveness in reducing proteinuria and delaying progression of chronic kidney disease. The major adverse effects associated with ACEI and ARB use are hyperkalemia, decrease in glomerular filtration rate (GFR), and erythropoietin resistance. The risk of hyperkalemia increases with the degree of decrease in GFR in the nondialysis population ${ }^{4}$.

The most common pattern of BP in dialysis patients is systolic hypertension associated with a wide pulse pressure due to atherosclerotic arterial stiffness. The main pathogenic mechanisms of hypertension in dialysis patients. Extracellular fluid overload is the most common feature in hypertensive dialysis patients. Indeed, insufficient volume removal is often the major factor responsible for dialysis-refractory hypertension ${ }^{5-9}$. In many patients, there is also an abnormal relationship between extracellular fluid volume and the reninangiotensin system (RAS) the circulating renin concentration is abnormally high for the exchangeable sodium levels. In addition, volume fluctuations such as plasma volume contraction during a dialysis session or interdialytic fluid overload result in activation of the sympathetic nervous system ${ }^{5}$. Erythropoietin (EPO) replacement therapy in anemic dialysis patients may also aggravate pre-existing hypertension. The aim of the work is to assess the anti hypertensive drugs treatment in CKD patients ${ }^{10-13}$.

\section{METHODOLOGY:}

This is a prospective observational study and includes information regarding CKD patients with co-morbidities like T2DM and HTN.

\section{RESULTS:}

This study is conducted among 15 patients which were of both gender i.e., males and females of above 20 yrs of age upto $80 \mathrm{yrs}$.

\section{The graph below indicates age distribution of patients among the sample size 15}

\begin{tabular}{|c|c|}
\hline & \\
AGE GROUPS & FREQUENCYDISTRIBUTION \\
\hline $20-30$ & 0 \\
\hline $30-40$ & 2 \\
\hline $40-50$ & 2 \\
\hline
\end{tabular}




\begin{tabular}{|c|c|}
\hline $50-60$ & 5 \\
\hline $60-70$ & 2 \\
\hline $70-80$ & 4 \\
\hline
\end{tabular}

\section{AGE DISTRIBUTION}

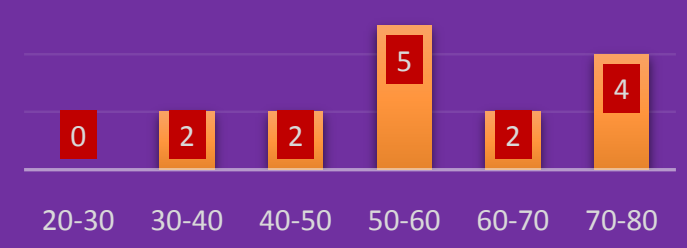

AGE GROUP

II.The graph below indicates gender distribution and includes 11 male patients and 4 female patients.

\begin{tabular}{|c|c|}
\hline $\begin{array}{c}\text { MALE } \\
\text { PATIENTS }\end{array}$ & FEMALE \\
PATIENTS \\
\hline 11 & 4 \\
\hline
\end{tabular}

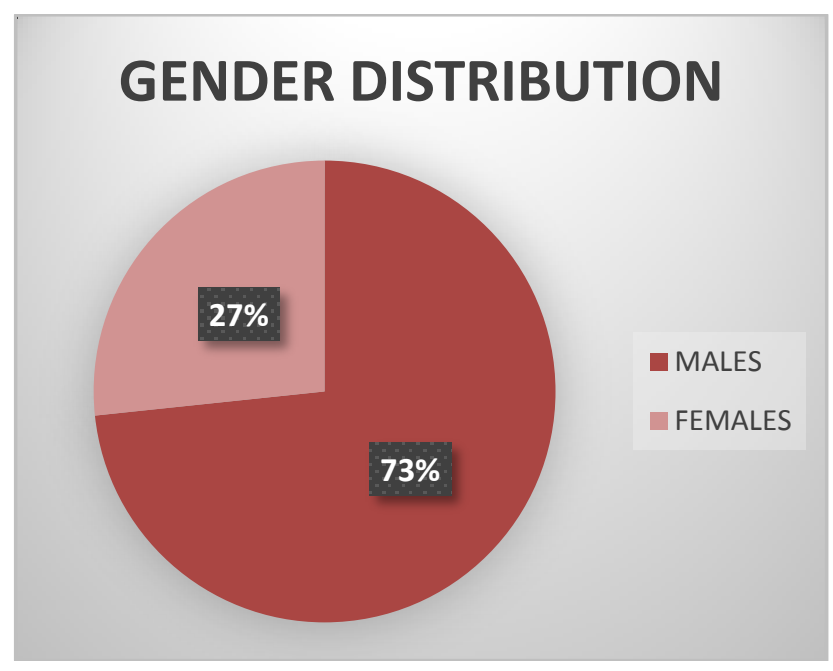

III. The graph plotted below represents past history among 15 patients.

\begin{tabular}{|c|c|}
\hline PAST HISTORY & NO.OF PATIENTS \\
\hline HTN & 2 \\
\hline DM & 2 \\
\hline HTN+DM & 6 \\
\hline HTN+CKD & 2 \\
\hline HTN+DM+CKD & 3 \\
\hline
\end{tabular}




\section{PAST HISTORY}

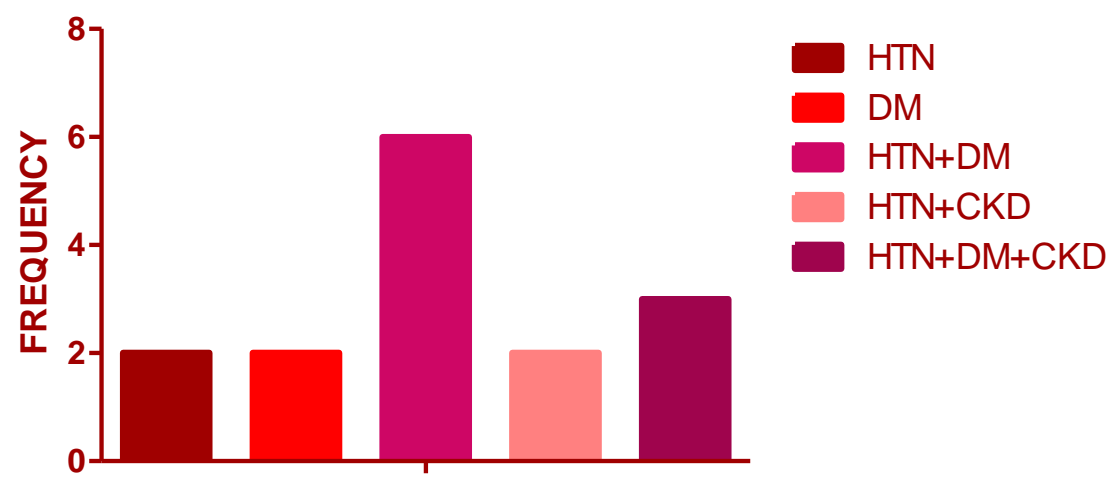

IV.This graph reveals information regarding final diagnosis among 15 nephrology patients of both gender with CKD STAGE 3-5.

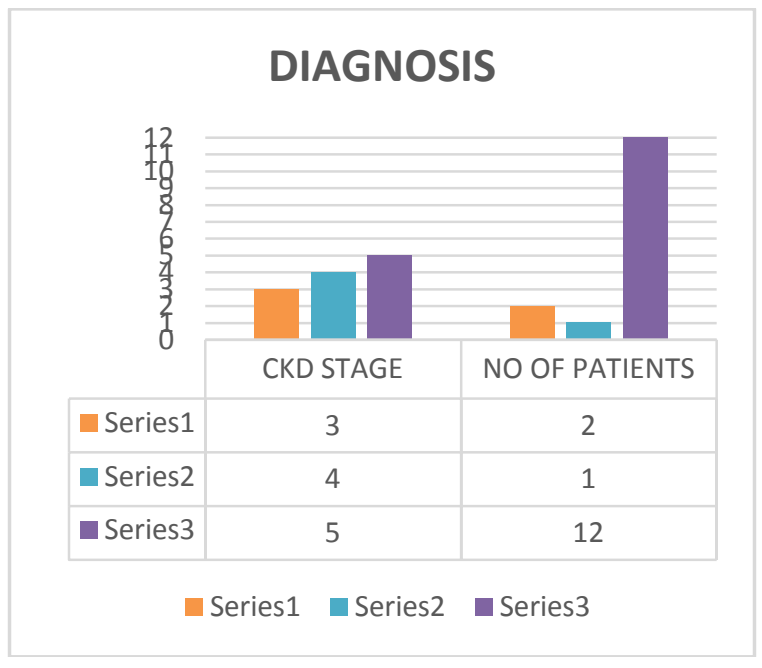

V.The graph below represents no of patients in various stages of CKD based on e GFR calculation.

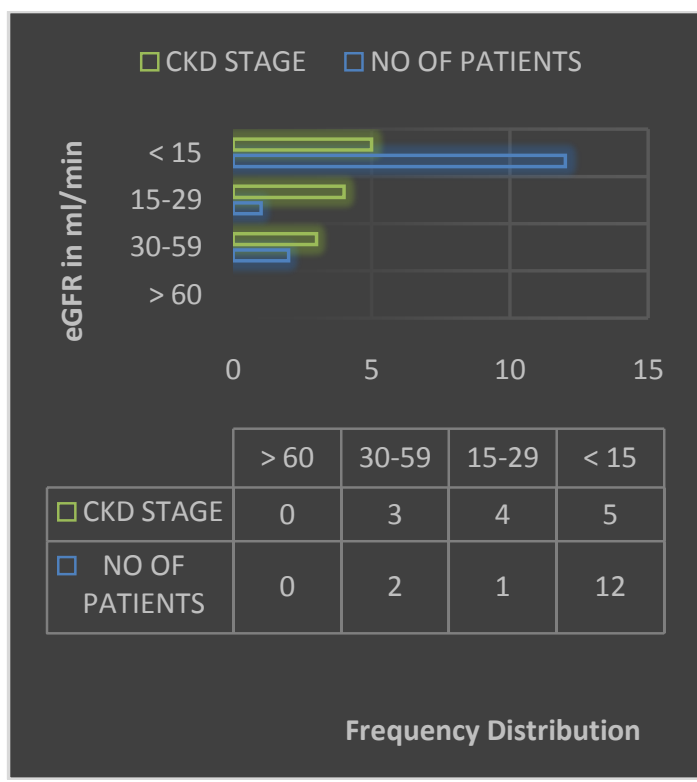

VI. The graph below indicates CKD patients who underwent dialysis regarding their stage of severity. Among 15 patients 7 were undergoing dialysis. 


\section{proportion of dialysis and non-dialysis patients}

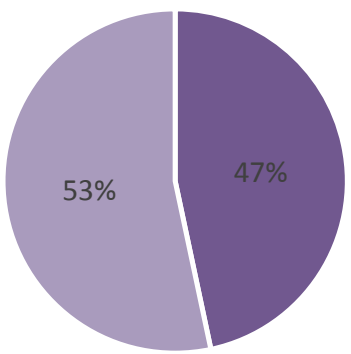

- dialysis $\quad$ non dialysis

VII.The graph below indicates combination of class of anti-hypertensives prescribed among 15 patients. Among 6 LD + CCB 5 are Furosemide and Amlodipine combination.

\begin{tabular}{|c|c|}
\hline $\begin{array}{c}\text { COMBINATION OF CLASS OF } \\
\text { ANTIHYPERTENSIVES }\end{array}$ & $\begin{array}{c}\text { NO. OF PATIENTS } \\
\text { PRESCRIBED WITH } \\
\text { COMBINATION }\end{array}$ \\
\hline LD+CCB & 6 \\
\hline LD+CCB+A2A & 1 \\
\hline LD+CCB+BB & 1 \\
\hline CCB+A2A+BB & 2 \\
\hline LD+CCB+A2A+BB & 1 \\
\hline LD+CCB+A2A+ & 1 \\
\hline ALPHA 2 BLOCKER & \\
\hline TD+CCB+A2A+ARB & \\
\hline
\end{tabular}

(LD-Loop diuretic, CCB- Calcium channel blocker, A2A- Alpha 2 agonist, BB-Beta blocker, TD-Thiazide diuretic, ARB-Angiotensin receptor blocker)

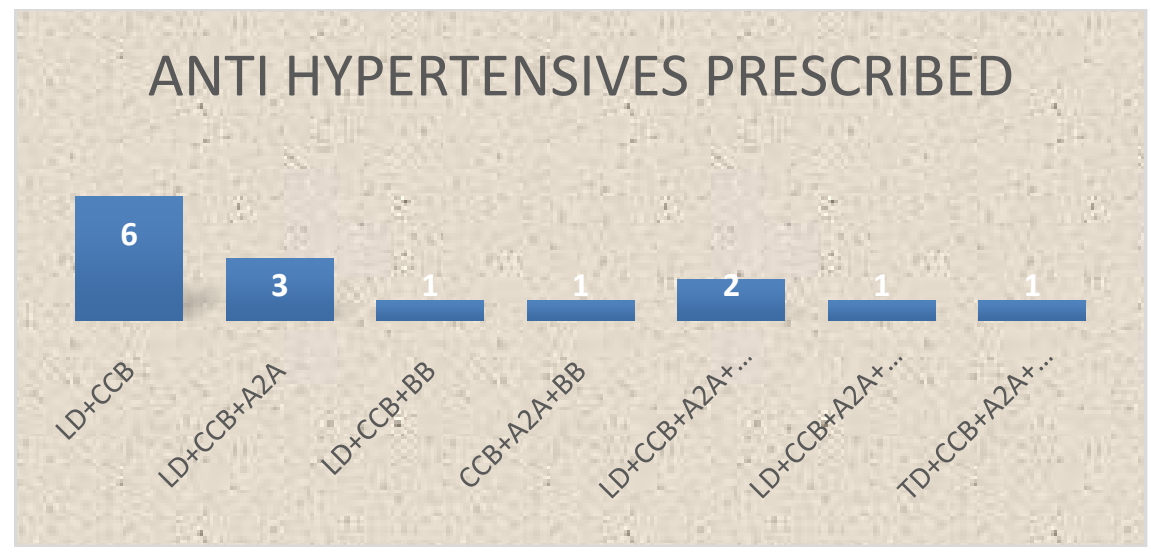


VIII. Pre-dialysis systolic BP Monitoring in 7 dialysis patients.

\begin{tabular}{|c|c|}
\hline PRE DIALYSIS SBP & FREQUENCY DISTRIBUTION \\
\hline $120-130$ & 0 \\
\hline $130-140$ & 1 \\
\hline $140-150$ & 1 \\
\hline $150-160$ & 4 \\
\hline$>160$ & 1 \\
\hline
\end{tabular}

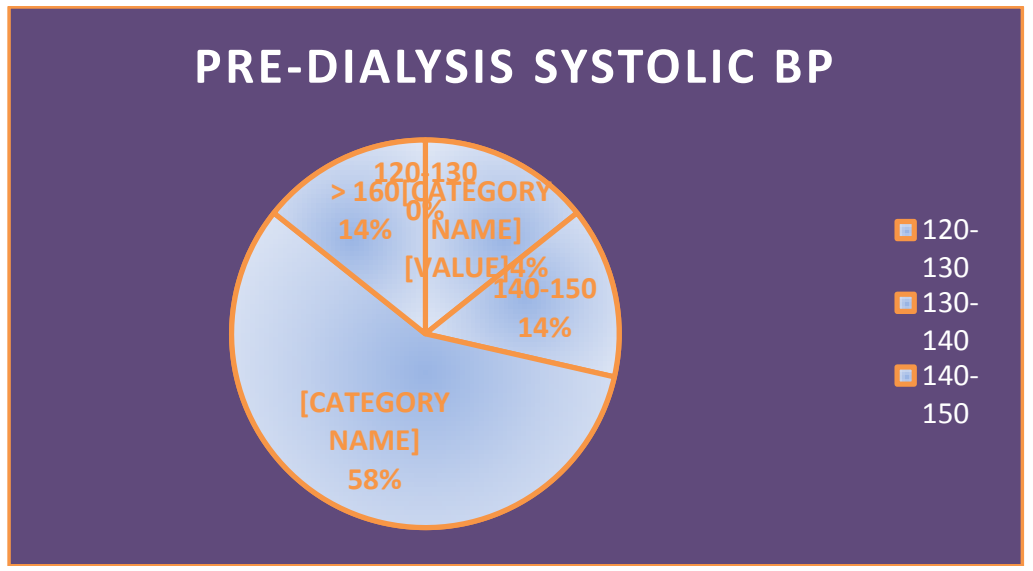

IX. Post-dialysis systolic BP monitoring in 7 dialysis patients.

\begin{tabular}{|c|c|}
\hline POST-DIALYSIS SBP & FREQUENCY DISTRIBUTION \\
\hline $120-130$ & 2 \\
\hline $130-140$ & 1 \\
\hline $140-150$ & 3 \\
\hline $150-160$ & 1 \\
\hline$>160$ & 0 \\
\hline
\end{tabular}

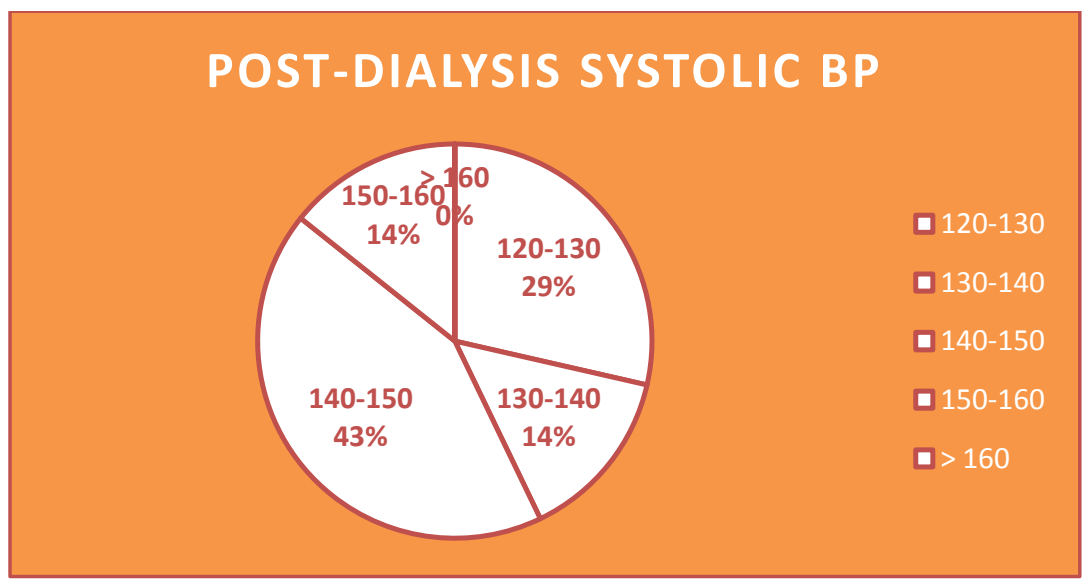

\section{DISCUSSION}

: Hypertension is common in hemodialysis patients and can often be difficult to control. Considering the high cardiovascular burden in hemodialysis patients, control of blood pressure is important to improve outcomes.

$>$ LOOP DIURETICS are most commonly used to treat uncomplicated HTN in patients with CKD. POTASSIUM SPARING DIURETICS and ALDOSTERONE BLOCKERS should be avoided in patients with severe CKD because of the rise in potassium that typically accompanies renal dysfunction.

$>$ First-line pharmacologic agents for blood pressure control RAAS inhibitors (either ACE-I or ARB) because of their documented benefit on left ventricular hypertrophy, pulse wave velocity, and causing efferent 
arteriolar dilation. This can cause an acute decline in GFR of more than $15 \%$ from baseline with proportional elevations in Sr.cr within the first week of initiating therapy which was most commonly occurs in patients with congestive heart failure.

$>$ Second line agents include the addition of beta-blockers (particularly in patients with coronary artery disease), combined $\alpha$ - and $\beta$-blockers in patients with heart failure, CCBs, and alternative agents such as direct vasodilators.

$>$ Most hemodialysis patients require a combination of antihypertensive agents to achieve adequate blood pressure control. Considering the high pill burden and high rates of noncompliance among hemodialysis patients, once daily (or thrice weekly) formulations should be used preferentially.

$>$ Nocturnal dosing of once daily antihypertensive medications is favored to control the nocturnal increase in blood pressure observed in many hemodialysis patients and to minimize the risk of intra-dialytic hypotension.

\section{CONCLUSION:}

This study is conducted among 15 CKD patients. For these 15 patients e GFR is calculated and stage of severity of CKD was found. Patients with T2DM and Hypertensive are mostly diagnosed with CKD. Loop diuretic (Furosemide) + Calcium channel blocker (Amlodipine) this combination is prescribed more which is found to be safe for CKD patients as for this combination dosage adjustment is not required. In our study among 15 CKD patients 7 dialysis patients were included, majority of the patients have controlled SBP with the antihypertensive combinations prescribed to them.

\section{ACKNOWLEDGEMENTS:}

The authors are very much thankful to Management and Principal, Dr.Garikapati. Devala Rao garu of KVSR Siddhartha College of pharmaceutical sciences, Vijayawada for their support and constant encouragement.

\section{REFFERENCES:}

[1] Semin Dial. Jula K. Inrig. Antihypertensive Agents in Hemodialysis Patients: A Current Perspective. PMC, 201O. 23(3): 290-297.

[2] Knauf H, Cawello W, Schmidt G, Mutschler E. The saluretic effect of the thiazide diuretic bemetizide in relation to the glomerular filtration rate. Eur J Clin Pharmacol1994; 46: 9-13.

[3] Akbari A, Knoll G, Ferguson D, McCormick B, Davis A, Biyani M. Angiotensin-converting enzyme inhibitors and angiotensin receptor blockers in peritoneal dialysis: Systematic review and meta-analysis of randomized controlled trials. Peritoneal Dialysis International, 2009, 29(5), 554-561.

[4] Kaissling B, Stanton BA. Adaptation of distal tubule and collecting duct to increased sodium delivery. I. Ultrastructure. Am J Physiol 1988; 255: F1256-F1268.

[5] Hebert LA, Wilmer WA, Falkenhain ME, Ladson-Wofford SE, Nahman NS, Rovin BH. Renoprotection: one or many therapies. Kidney Int 2001; 59: 1211-1226.

[6] Wilcox CS. Diuretics. In Brenner BM, Rector FC, eds. The Kidney, 4th edn. W. B. Saunders Co., Philadelphia; 1991: 2123-2148.

[7] Otilie Weinbergová, Rudolf Metelka, Jiř́i Vymětal, Karel Konečný, Zdena Kosatíková.

[8] Telmisartan in the treatment of hypertension in patients with chronic renal insufficiency. Biomed. Papers, 2004, 148(1), 69-73.

[9] Knauf H, Mutschler E. Diuretic effectiveness of hydrochlorothiazide and furosemide alone and in combination in chronic renal failure. J Cardiovasc Pharmacol 1995; 26: 394-400.

[10] Dussol B, Moussi-Frances J, Morange S, Somma-Delpero C, Mundler O, Berland Y. A randomized trial of furosemide vs hydrochlorothiazide in patients with chronic renal failure and hypertension. Nephrol Dial Transplant, 2005, 20(2): 349-353.

[11] Loon NR, Wilcox CS, Unwin RJ. Mechanism of impaired natriuretic response to furosemide during prolonged therapy. Kidney Int 1989; 36: 682-689.

[12] A. Sayin, R. Mutluay, and S. Sindel. Quality of Life in Hemodialysis, Peritoneal Dialysis, and Transplantation Patients. Transplant Proc. 2007, 39(10):3047-53.

[13] Stanton BA, Kaissling B. Adaptation of distal tubule and collecting duct to increased sodium delivery. II. $\mathrm{Na}^{+}$and $\mathrm{K}^{+}$transport. Am J Physiol 1988; 255:F1269-F1275.

[14] Ellison DH. The physiological basis of diuretic synergism: its role in treating diuretic resistance. Ann Intern Med 1991; 114: 886-894. 